\title{
Análise das contribuições econômicas da Ferrovia Norte-Sul nos municípios goianos
}

\author{
Aline Carvalho de Castro \\ Mestre em Economia (FACE/UFG). Professora na Faculdade Sul - Americana (FASAM). \\ E-mail: aline_carvalhodecastro@hotmail.com
}

\section{Fabricio Schlag}

Mestre em Engenharia Elétrica (UNB). Professor na Universidade Estadual de Goiás (UEG).

E-mail: fabricioschlag@gmail.com

\section{Flávia Rezende Campos}

Doutora em Geografia (IESA/UFG). Professora de Economia (FACE/UFG).

E-mail: flaviarezende@hotmail.com

Resumo: O objetivo do trabalho consiste em analisar as contribuições econômicas da Ferrovia Norte-Sul (FNS) nos municípios goianos. É feito uma análise descritiva de dados do PIB per capita de 2003 a 2013, arrecadação tributária e renda do trabalho, ambos de 2003 a 2015. Os municípios goianos analisados são aqueles cortados pelo trecho Palmas/TO - Anápolis/GO. A evolução desses dados ao longo do período supracitado revela que apenas a construção da FNS não foi suficiente para contribuir para o crescimento econômico dos municípios, mensurado pelo produto interno, ou seja, seria necessário também estimular atividades de apoio que geram efeitos de transbordamento na economia. A renda do trabalho e a arrecadação tributária apresentam uma tendência de melhora nos indicadores nos anos de auge da construção da FNS, mas não se mantêm após o término das obras. Esse fato pode ser explicado pelo fato de a ferrovia não estar em operação, dificultando a consolidação dos investimentos nos municípios.

Palavras-chave: Infraestrutura de Transporte, Ferrovia Norte-Sul; Goiás.

Abstract: The objective of this work is to analyze the economic contributions of the North-South Railroad (NSR) in the counties of Goiás state. A descriptive analysis of GDP per capita data from 2003 to 2013 is made. Tax collection and labor income, both from 2003 to 2015. The analyzed counties of Goiás are those cut by the Palmas/TO - Anápolis I GO railway. The evolution of these data during the above mentioned period reveals the construction of the NSR alone was not sufficient to contribute to the economic growth of the counties, measured by the domestic product, in other words, it would also be necessary to stimulate support activities that generate spillover effects in the economy. Labor income and tax collection tend to improve indicators in the peak years of the NSR construction, but are not maintained after the completion of the construction. This fact can be explained by the fact that the railroad is not in operation, making it difficult to consolidate investments in the counties.

Key-words: Transport Infrastructure, North-South Railway; Goiás.

JEL Code: R4. 


\section{INTRODUÇÃO}

A implantação da Ferrovia Norte-Sul (FNS) é um projeto em andamento desde 1982 e ainda em fase de construção em alguns trechos, apresentando como uma tentativa de promover maior integração nacional cortando o território brasileiro de norte a sul. De acordo com a VALEC (2002), o objetivo principal da FNS é desenvolver, pela parceria público-privada, um eixo de transporte competitivo entre as regiões norte e sul do país que represente uma alternativa mais econômica para o transporte de cargas a longa distância, permitindo o acesso da região central do Brasil até os portos do norte do país (Belém e São Luís), estabelecendo a integração inter-regional e formando um sistema de transporte destinado ao mercado externo e interno.

Atualmente, a construção da FNS está dividida em sete trechos, são eles: Barcarena/PA - Açailândia/MA; Açailândia/MA - Palmas/TO; Palmas/TO - Anápolis /GO; Ouro Verde/GO - Estrela d'Oeste/SP; Estrela d'Oeste - Panorama/SP; Panorama /SP Chapecó /SC; Chapecó /SC - Rio Grande /RS. O primeiro trecho foi concluído em 2012, já o segundo foi entregue em 2010 e se encontra em operação comercial pela subconcessionária Ferrovia Norte Sul S.A., criada pela Vale S.A. O trecho entre os municípios de Palmas /TO e Anápolis/GO tem $855 \mathrm{~km}$ de extensão, foi construído e entregue no dia 22 de maio de 2014. Com a inauguração do trecho, a FNS se constitui como a ferrovia estruturadora do sistema ferroviário nacional, facilitando o acesso a vários portos e corredores de exportação. Os demais trechos ainda se encontram em fase de construção ou contratação (VALEC, 2016).

A importância econômica da construção da FNS para Goiás se torna cada vez mais presente à medida que indústrias se instalam no estado para consolidar o desenvolvimento da região, propiciando assim, o aquecimento do comércio e a geração de empregos. Os benefícios para os municípios podem apresentar um efeito de transbordamento, pois além de atrair investimentos industriais e impulsionar o comércio, a região pode experimentar um aumento da valorização fundiária e crescimento das atividades extrativas e mineradoras, sobretudo nos municípios do norte do estado. A instalação de novas empresas, seja comercial ou industrial, gera maior arrecadação tributária aos municípios, que podem investir em infraestrutura básica para a população, dando suporte ao crescimento e promovendo maior qualidade de vida aos habitantes.

O objeto de estudo desta pesquisa estabeleceu como recorte espacial a análise dos municípios goianos que fazem parte do trecho Palmas/TO - Anápolis/TO. São eles: Porangatu, Formoso, Santa Tereza, Estrela do Norte, Mara Rosa, Alto Horizonte, Campinorte, Uruaçu, São Luiz do Norte, Santa Isabel, Rialma, Ceres, Rianápolis, Jaraguá, Jesúpolis, São Francisco do Goiás, Petrolina de Goiás, Ouro Verde, Nerópolis, Campo Limpo e Anápolis. Nestes municípios as obras da FNS já foram entregues, no entanto, a ferrovia não se encontra efetivamente em funcionamento. Isso implica que o objetivo do estudo é captar a contribuição das obras de construção da ferrovia, como a implementação dos trilhos e dos pátios de integração multimodal. Foram escolhidas três variáveis econômicas para analisar a influência da FNS sobre estes municípios: PIB per capita, renda do trabalho e arrecadação tributária, em período que compreende início, auge e término das obras. Vale ressaltar também, que no estado de Goiás 
p. 33 - Análise das contribuições econômicas da Ferrovia Norte-Sul nos municípios goianos

existem cinco pátios de integração multimodal da FNS nos seguintes municípios: Uruaçu, Porangatu, Santa Isabel, Jaraguá e Anápolis.

Desta forma, a questão que se propõe responder com a pesquisa é a seguinte: quais as contribuições econômicas da Ferrovia Norte-Sul nos municípios goianos que fazem parte do trecho Palmas /TO - Anápolis /GO? Trabalha-se com a hipótese de que os municípios foram contemplados com um incremento das variáveis PIB per capita, renda do trabalho e arrecadação tributária durante os anos de construção da ferrovia e dos pátios de integração multimodal. Contudo, acredita-se que após o período de construção da FNS essas variáveis podem ter sofrido uma variação negativa, contando que a ferrovia não está ainda em pleno funcionamento.

O principal objetivo do presente trabalho consiste em analisar as contribuições econômicas da Ferrovia Norte Sul nos municípios goianos - que contemplam a passagem dos trilhos - desde a sua construção até o momento. Especificamente pretende-se discorrer sobre a importância da infraestrutura de transporte e a gestão logística do transporte de cargas para o desenvolvimento econômico; investigar na literatura existente acerca da importância da construção da FNS; realizar uma análise descritiva da evolução das seguintes variáveis econômicas nos municípios comtemplados pela passagem da FNS em Goiás: PIB per capita, renda do trabalho e arrecadação tributária.

Em relação aos dados quantitativos as principais fontes utilizadas são: Instituto Mauro Borges de Estatística e Estudos Socioeconômicos (IMB), para os dados relativos ao PIB per capita municipal; Relação Anual de Informações Sociais (RAIS), para a renda do trabalho; e o Tesouro Nacional, para os dados de arrecadação tributária municipal (Imposto Sobre Serviços de Qualquer Natureza - ISSQN). Tais dados foram utilizados para realizar a análise descritiva e acompanhamento da evolução dos indicadores nos municípios contemplados pela FNS em Goiás.

\section{REVISÃO DA LITERATURA}

\subsection{Importância da Infraestrutura de Transportes}

Muitos autores reconhecem a ligação entre infraestrutura de transporte e crescimento econômico. Sabe-se que o crescimento econômico traz consigo um aumento da demanda por sistemas de transporte eficientes e capazes de corresponder a essa nova procura, possibilitando o acesso mais abrangente a mercados de produtos e matérias-primas. Desta forma, a fragilidade do sistema de transporte pode comprometer o processo de desenvolvimento econômico, tanto pelo fato de restringir possibilidades de ganhos do comércio, quanto por afetar negativamente outros setores (ARAÚJO, 2006).

Os transportes como atividade de suporte à produção de bens e serviços são fundamentais para melhor aproveitar o potencial de produção de uma região, pois interagem com o desenvolvimento da economia como um todo, tendo implicações com as transformações na estrutura das demandas intermediária e final e, com as modificações e combinações dos fatores de produção; além de se relacionar com a 
estruturação do espaço geográfico e econômico, ao condicionar os padrões de organização do território e a localização de atividades (BARAT, 2007).

Os efeitos multiplicadores gerados pelos investimentos em infraestrutura de transporte são imprescindíveis, sobretudo em termos de geração de renda e emprego, pois tendem a afetar os setores mais dinâmicos da economia e a propagarem os efeitos dessas variáveis. Além disso, contribuem, também, para eliminar obstáculos à propagação de inovações, alargando os mercados e possibilitando maior mobilidade dos fatores de produção (ARAÚJO, 2006; BARAT, 2007). Um dos exemplos desses efeitos ocorreu no município de Gurupi (TO), em que a construção da FNS contribuiu para o desenvolvimento local, aumentando a renda e gerando novos postos de trabalho (CORREIA E OLIVEIRA, 2010).

Com base nesta interpretação, Barat (2007, p.39) destaca ainda que os transportes

[...] estão na linha de frente das questões ligadas ao desenvolvimento econômico e social, à geração de empregos, à ocupação territorial, à energia e ao meio ambiente. Isto porque respondem por importantes parcelas da formação de capital, da ocupação de mão-de-obra, do consumo de insumos energéticos e da formação de clusters produtivos e eixos de desenvolvimento.

Para Caixeta-Filho e Martins (2011) a disponibilidade de uma infraestrutura adequada proporciona ganhos de eficiência e redução dos custos que se configuram em elevação da remuneração dos fatores de produção, o que estimula o investimento e o emprego. Sem contar que um sistema de infraestrutura satisfatório pode provocar um efeito de transbordamento, permitindo condições para novos investimentos.

Os transportes possuem quatro funções básicas: 1) elevação na disponibilidade de bens, permitindo acesso a produtos que de outra forma não estariam disponíveis à sociedade; 2) possibilidade de expansão dos mercados; 3) papel potencial de romper monopólios, provocado pelo isolamento geográfico; 4) possibilidade de especialização regional da produção proporcionada pela vantagem absoluta de custos ou pela vantagem comparativa de custos (CAIXETA FILHO E MARTINS, 2011).

Castro (1995) apud Caixeta-Filho e Martins (2011) enfatiza ainda a questão logística, pois a busca em atender aos requisitos dos consumidores quanto à qualidade dos insumos e produtos, prazos de entrega, assistência técnica e inovações, têm garantido com que a eficiência do sistema logístico se torne condição básica para a competitividade de todos os setores da economia.

Desta forma, investigar a relação entre infraestrutura de transporte e crescimento econômico torna-se o escopo principal desta pesquisa, com ênfase no transporte ferroviário no estado de Goiás, no sentido da sua importância econômica para o desenvolvimento regional e incremento em variáveis econômicas relevantes. $\mathrm{Na}$ próxima sessão serão apresentados estudos empíricos que tiveram como base a investigação dos efeitos da construção e implantação de infraestrutura de transporte ferroviário, em especial da FNS. 
p. 35 - Análise das contribuições econômicas da Ferrovia Norte-Sul nos municípios goianos

\subsection{Referencial Empírico}

O debate acerca do transporte ferroviário no Brasil tem ganhado espaço na literatura e nos trabalhos acadêmicos nos últimos anos. Dado a importância do tema, boa parte dos trabalhos na área tem sido direcionada ao estudo não apenas da avaliação das políticas públicas, mas também dos impactos econômicos referentes aos investimentos despendidos nas regiões e nas áreas de influência, bem como aqueles que discutem a importância das ferrovias no âmbito nacional. Desta forma, são utilizadas várias abordagens metodológicas para atingir os objetivos propostos, dado as diferentes formas disponíveis de se avaliar os efeitos dos investimentos no setor de transportes.

Adorno (1999) buscou elucidar a participação dos sujeitos concretos no período de dez anos da construção da FNS. Para a montagem do roteiro histórico, utilizou-se de entrevistas e depoimentos dos cidadãos das regiões, além de informações da VALEC, Companhia Vale do Rio Doce (CVRD) e Ministério do Exército.

Mesmo quando ainda não passava de um projeto, a construção da FNS possibilitou a resistência de uma política de planejamento estatal do uso do solo numa escala regional, toda sua abrangência permitiu um foco de recuperação de planos integrados de desenvolvimento, alcançando a escala nacional por se inserir nas estruturas de transporte e desenvolvimento de setores multimodais, integrando o Centro - Norte, Centro - Leste e Nordeste. Assim, o projeto da FNS pôde incorporar uma nova chance para o papel da integração nacional. A ferrovia proporcionou ainda o crescimento da produção de soja no sul do Maranhão e a implantação de programas de desenvolvimento da produção de grãos, que se estenderam para os estados do Piauí e Tocantins, permitindo o escoamento da produção para o sul do Pará e Mato Grosso (ADORNO, 1999).

Batista Filho (2009) utilizou o modelo insumo - produto para mensurar os impactos dos investimentos na implantação da FNS no estado do Tocantins. Os resultados mostraram que os impactos gerados pelos investimentos da construção da ferrovia poderiam gerar um aumento de $\mathrm{R} \$ 4.939,00$ sobre o Valor Bruto do Produto na região caso todos os investimentos previstos no Programa de Aceleração do Crescimento - PAC e pela VALEC fossem efetivados. A conclusão das obras iria gerar um aumento dos rendimentos na área de influência direta da ferrovia, em cerca de 160\%. Com relação ao emprego gerado com a conclusão das obras esperava-se um crescimento de $20,64 \%$ das ocupações.

Campos e Castro (2014) analisaram as contribuições econômicas da construção da FNS nos municípios do centro-norte goiano. Para tal, acompanharam a progressão do PIB per capita, arrecadação tributária municipal e renda do trabalho no período de 2003 a 2010 e chegaram à conclusão de que a arrecadação tributária e a renda do trabalho foram impactadas positivamente nos municípios analisados durante o período de construção da ferrovia.

Campos (2015) analisou a influência da Ferrovia Norte Sul no desenvolvimento regional do território goiano. Os resultados mostraram que o transporte ferroviário em Goiás contribuiu para colocar a economia goiana frente à economia nacional, sobretudo 
ao longo do século XX, com a construção da Estrada de Ferro Goiás em 1913. Verificouse ainda, com base em previsões realizadas nos municípios tocantinenses, uma tendência em termos de agregação de benefícios à economia goiana, de modo a ampliar sua integração em relação à economia nacional. Além disso, constatou-se que as variáveis PIB per capita, arrecadação tributária e renda do trabalho sofreram um incremento durante o período de construção da ferrovia.

Ao discutir os resultados obtidos, as pesquisas acima mencionadas mostram a importância, bem como os impactos econômicos da construção da FNS nos municípios e estados estudados. A maioria dos trabalhos relacionados à construção da FNS tem como base aqueles estados do norte do país, como o Maranhão e o Tocantins. Para o estado de Goiás, os trabalhos na área ainda são limitados e ficam restritos, em sua maioria, a pesquisas de campo, sem análise de dados quantitativos que possam refletir ou prever a influência e contribuição da FNS para o estado.

\section{DISCUSSÃO}

O objetivo desta seção consiste em apresentar um breve histórico da construção da Ferrovia Norte-Sul. Em seguida é realizada uma análise da evolução dos indicadores econômicos do PIB per capita, renda do trabalho e arrecadação tributária, nos municípios goianos servidos pelos trilhos do trecho Palmas/TO - Anápolis/GO.

\subsection{A Ferrovia Norte-Sul}

Os projetos de implantação de transporte ferroviário no Brasil desde o início não contaram com estratégias de integração territorial. Algumas regiões, como a Sul e Sudeste contavam com a maior parte da extensão das vias férreas, em detrimento daquelas que não pertenciam aos eixos de produção da economia agroexportadora, como as Regiões Norte e Centro-Oeste do país. Mesmo a partir da década de 1930 com a difusão do transporte rodoviário no país, ainda não se nota a existência de projetos de integração de transportes com a participação do modal ferroviário.

De acordo com Diário da Manhã (1988), o primeiro plano de integração hidrovia-ferrovia data de 1874, desenvolvido pelo engenheiro André Rebouças, que previa a implantação de um sistema ferroviário que ligasse o Brasil de Norte a Sul e de Leste a Oeste, baseado no sistema quadriculado inspirado no plano ferroviário norte americano. Este projeto foi seguido de vários outros com o mesmo intuito, como o Plano Bicalho (1881) e o Plano Bulhões (1882), mas nenhum deles chegou a ser aprovado pelo parlamento ou implantado.

No ano de 1913 ressurge a ideia de um plano de integração de transporte terrestre de Norte a Sul do país, desenvolvido por Paulo de Frontin, que almejava prolongar a linha de Pirapora, em Minas Gerais até Belém, intercalando os modais rodoviário e ferroviário. A obra chegou a ter início, com a construção de uma ponte sobre o Rio São Francisco, inaugurada em 1922, mas a obra não teve continuidade desde então. Em 1934 é aprovado o primeiro Plano Geral de Viação Nacional, demonstrando preocupação com a integração do território nacional. Durante o governo 
p. 37 - Análise das contribuições econômicas da Ferrovia Norte-Sul nos municípios goianos

militar alguns debates foram realizados a fim de discutir as melhores maneiras de ligação do país, passando a discussão por alguns modais, optou-se pelo transporte rodoviário (ADORNO, 1999).

A implantação da Ferrovia Norte-Sul (FNS), projeto que teve início no ano de 1982 e retomado no Governo Lula com Programa de Aceleração do Crescimento (PAC), representa um esforço para promover maior integração nacional cortando o território brasileiro de norte a sul, resgatando projetos do setor ferroviário. O intuito inicial consistia em promover, pela parceria público-privada, um eixo de transporte competitivo entre as regiões norte e sul do país, que represente uma alternativa mais econômica para o transporte de cargas a longa distância, permitindo o acesso da região central do Brasil até os portos do norte do país (Belém e São Luís), estabelecendo a integração inter-regional e formando um sistema de transporte destinado ao mercado externo e interno (VALEC, 2002).

Os principais objetivos com a construção da FNS consistem em estabelecer alternativas mais econômicas para o fluxo de cargas; promover a ocupação econômica do cerrado brasileiro, incentivar a multimodalidade no transporte de cargas; promover uma logística exportadora competitiva com acesso aos principais portos de escoamento no Brasil e; incentivar investimentos que irão incrementar a produção, induzir novos negócios e atividades industriais. Os benefícios esperados além de redução nos custos de comercialização e transporte, também envolvem melhoria do desempenho da malha ferroviária nacional e aumento da competitividade nos produtos brasileiros no cenário internacional (VALEC, 2017).

De acordo com a VALEC (2017) a FNS foi projetada para promover a interligação nacional, minimizar os custos de transporte e integrar as regiões brasileiras, por meio de conexões com outras ferrovias tanto as novas quanto aquelas já existentes. Sua construção teve início na década de 1980 a partir da ligação com a Estrada de Ferro Carajás (EFC). O traçado inicial da FNS previa a construção de 1550 quilômetros de Açailândia/MA até Anápolis/GO. No entanto, no ano de 2008 foram incorporados os trechos de Barcarena/PA a Açailândia/MA e, de Ouro Verde/GO a Panorama/SP. Em 2012 foram incorporados mais dois trechos de Panorama/SP a Chapecó/SC e, de Chapecó/SC a Rio Grande/RS. Desta forma, a FNS Barcarena/PA - Rio Grande/RS terá 4787 quilômetros de extensão, cumprindo seu papel de espinha dorsal do transporte ferroviário no Brasil, integrando as regiões do país de norte a sul. Desses, 1575 quilômetros da ferrovia já se encontram em operação de Açailândia (MA) a Anápolis (GO). Embora, o trecho Palmas/TO - Anápolis/GO se encontre em operação pela VALEC, o número de cargas até então transportas é muito pequeno e abaixo do potencial da ferrovia.

O trecho de Palmas/TO - Anápolis/GO têm 855 km de extensão, sendo entregue no dia 22 de maio de 2014. Os municípios goianos que são servidos pela passagem dos trilhos no sentido norte-sul são Porangatu, Formoso, Santa Tereza, Estrela do Norte, Mara Rosa, Alto Horizonte, Campinorte, Uruaçu, São Luiz do Norte, Santa Isabel, Rialma, Ceres, Rianápolis, Jaraguá, Jesúpolis, São Francisco do Goiás, Petrolina de Goiás, Ouro Verde, Nerópolis, Campo Limpo e Anápolis, como podem ser observados na Figura 1. 
Os municípios que contam com a passagem dos trilhos do trecho Palmas/TO Anápolis/GO não são os únicos que a sentir os efeitos gerados pela construção da FNS. Um estudo realizado pela SEGPLAN (2008) mostra que a área de influência da FNS em Goiás compreende as seguintes regiões de planejamento: Norte goiano, Noroeste goiano, Centro goiano e parte do Nordeste goiano, entorno do Distrito Federal e Oeste goiano, totalizando 130 municípios. Goiás contará ainda com cinco pátios multimodais nos municípios de Anápolis, Jaraguá, Santa Isabel, Uruaçu e Porangatu, que começaram a serem construídos no ano de 2008.

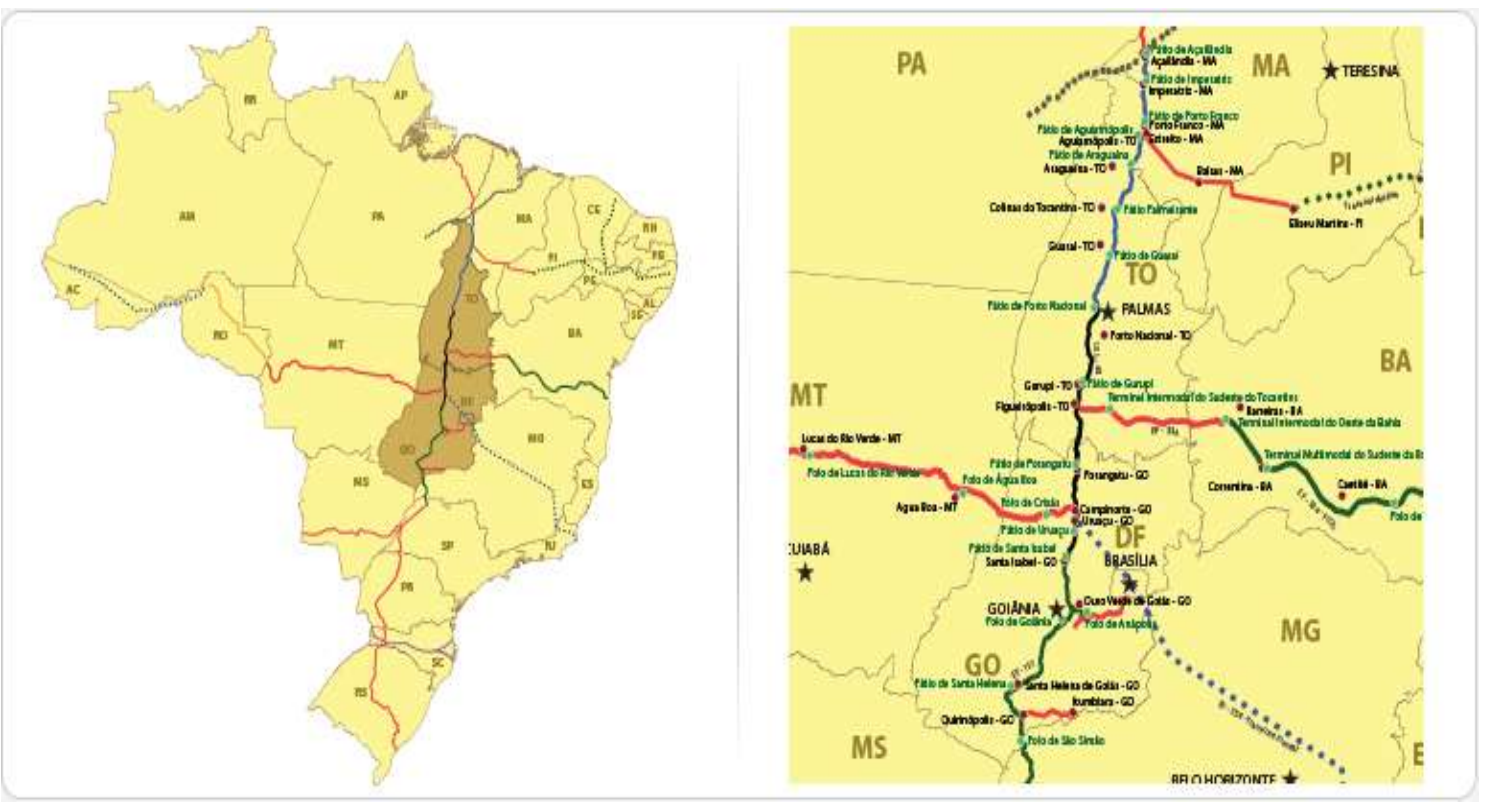

Figura 1. Mapa do trecho Palmas/TO - Anápolis/GO.

Fonte: VALEC (2017).

Na área de influência da FNS os índices de renda e emprego são concentrados, aproximadamente de $40 \%$ do emprego formal vem de apenas cinco municípios: Anápolis, Luziânia, Goianésia, Formosa e Inhumas. Os municípios mais dinâmicos são Anápolis, Campo Limpo de Goiás e Cristalina. A riqueza dessa área também se mostra concentrada: aproximadamente 52\% do Produto Interno Bruto vêm de apenas dez municípios, dos quais 19\% são provenientes da cidade de Anápolis. Desta forma, configura-se em uma região que necessita de políticas de desenvolvimento socioeconômico, sobretudo para aqueles municípios mais desprovidos de investimentos. (SEGPLAN, 2008).

\subsection{Análise Descritiva dos Dados}

Para se atingir os objetivos propostos do trabalho, além da realização de pesquisa bibliográfica, também foi realizada uma análise descritiva de dados como o PIB per capita de 2003 a 2013, obtido pelo Instituto Mauro Borges de Estatística e Estudos Socioeconômicos (IMB); renda média do trabalho de 2003 a 2015, obtido pela Relação Anual de Informações (RAIS) e; arrecadação tributária municipal de 2003 a 2015, medida pelo Imposto sobre Serviços de Qualquer Natureza (ISSQN), obtido pelo Sistema 
de Informações Contábeis e Fiscais do Setor Público Brasileiro (Siconfi). Todos os dados foram deflacionados utilizando o Índice Geral de Preços - Disponibilidade Interna (IGPDI), calculado pela Fundação Getúlio Vargas (FGV) com base em 2016.

Os municípios cujas variáveis foram analisadas são aqueles servidos pela passagem dos trilhos da FNS em Goiás que fazem parte do trecho Palmas/TO Anápolis/GO: Porangatu, Formoso, Santa Tereza, Estrela do Norte, Mara Rosa, Alto Horizonte, Campinorte, Uruaçu, São Luiz do Norte, Santa Isabel, Rialma, Ceres, Rianápolis, Jaraguá, Jesúpolis, São Francisco do Goiás, Petrolina de Goiás, Ouro Verde, Nerópolis, Campo Limpo e Anápolis. O período de análise compreende os anos de 2003 a 2015, pois se referem ao início da construção da FNS no estado de Goiás, bem como seu auge e a fase de conclusão das obras.

A Tabela 1 mostra a evolução do PIB per capita municipal de 2003 a 2013. Podese perceber que, com exceção dos municípios de Alto Horizonte e Anápolis ${ }^{1}$, o período de construção da FNS, com o seu auge em 2010, impactou timidamente a produção dos municípios servidos pela passagem dos trilhos. Após esse ano, o incremento no PIB per capita coincide com um período de crescimento econômico nacional, não podendo afirmar que o resultado positivo tenha sido em virtude da FNS, dado que essa ainda não se encontra em operação.

Ao analisar o PIB per capita dos municípios que contam com a passagem dos trilhos da FNS, faz-se necessário observar a evolução da população dessas localidades, por conta da influência que o incremento populacional poderia impactar nessa variável. Porém, de acordo com os dados do IMB (2016), não houve modificações significativas na população estimada no período estudado, especialmente nos municípios servidos com os pátios de integração (Tabela 2).

Ao observar a evolução do PIB per capita (Gráfico 1) nos municípios onde foram construídos os pátios de integração multimodal: Jaraguá, Porangatu, Uruaçu e Santa Isabel, percebe-se que apenas a construção dos pátios não foi suficiente para incrementar o produto. Apesar de se tratar de grandes obras de infraestrutura que movimentam uma parte da renda municipal, faz-se necessário a implementação de outras políticas que dão suporte à infraestrutura instalada nas localidades, para que o empreendimento possa alavancar de fato o produto municipal. A própria operação da FNS poderia gerar um incremento do produto municipal, conforme preconizado pela literatura vigente sobre a relação entre a infraestrutura de transporte e o crescimento econômico.

\footnotetext{
${ }^{1}$ É importante lembrar que Anápolis é um município que possui uma estrutura econômica diferente dos demais e, o alto PIB per capita verificado em Alto Horizonte a partir de 2007 pode ser explicado pela instalação de uma mineradora (extração de cobre e ouro).
} 
Tabela 1. PIB per capita municipal de 2003 a 2013 - municípios selecionados

\begin{tabular}{|c|c|c|c|c|c|c|c|c|c|c|c|}
\hline Município & 2003 & 2004 & 2005 & 2006 & 2007 & 2008 & 2009 & 2010 & 2011 & 2012 & 2013 \\
\hline Alto Horizonte & 10.063 & 9.999 & 11.591 & 15.627 & 181.496 & 173.221 & 198.933 & 246.927 & 264.430 & 231.483 & 137.788 \\
\hline Anápolis & 17.689 & 17.073 & 17.808 & 22.557 & 25.360 & 30.583 & 39.619 & 44.281 & 48.202 & 43.917 & 42.285 \\
\hline Campinorte & 8.843 & 10.660 & 10.399 & 10.155 & 11.516 & 12.073 & 13.617 & 12.918 & 17.797 & 18.711 & 19.296 \\
\hline $\begin{array}{l}\text { Campo Limpo de } \\
\text { Goiás }\end{array}$ & 10.396 & 9.554 & 8.399 & 8.509 & 8.150 & 8.900 & 9.354 & 9.729 & 11.806 & 12.478 & 13.353 \\
\hline Ceres & 12.972 & 12.849 & 13.275 & 15.318 & 15.789 & 15.117 & 16.665 & 15.788 & 19.775 & 23.132 & 22.404 \\
\hline Estrela do Norte & 9.229 & 9.066 & 9.898 & 10.218 & 11.735 & 11.619 & 12.301 & 12.930 & 18.435 & 14.002 & 16.108 \\
\hline Formoso & 7.765 & 7.790 & 7.906 & 8.568 & 8.596 & 9.065 & 9.549 & 10.498 & 11.379 & 10.628 & 11.952 \\
\hline Jaraguá & 9.823 & 9.764 & 10.115 & 10.911 & 11.463 & 11.359 & 11.769 & 12.220 & 14.736 & 15.002 & 15.348 \\
\hline Jesúpolis & 8.245 & 8.180 & 8.278 & 8.255 & 8.396 & 8.626 & 9.374 & 10.223 & 10.217 & 10.602 & 11.755 \\
\hline Mara Rosa & 9.922 & 9.661 & 9.480 & 9.691 & 11.501 & 12.165 & 13.165 & 13.606 & 14.273 & 15.517 & 16.630 \\
\hline Nerópolis & 18.577 & 19.134 & 19.127 & 21.614 & 23.513 & 22.169 & 27.401 & 21.947 & 23.877 & 27.033 & 28.374 \\
\hline $\begin{array}{l}\text { Ouro Verde de } \\
\text { Goiás }\end{array}$ & 12.419 & 11.633 & 10.440 & 10.811 & 10.939 & 10.919 & 13.108 & 16.310 & 20.392 & 25.411 & 45.626 \\
\hline $\begin{array}{l}\text { Petrolina de } \\
\text { Goiás }\end{array}$ & 9.695 & 9.042 & 9.013 & 9.241 & 9.751 & 9.796 & 11.644 & 12.656 & 12.138 & 11.645 & 12.405 \\
\hline Porangatu & 12.058 & 11.085 & 11.488 & 12.425 & 13.188 & 12.835 & 13.497 & 13.482 & 17.297 & 19.067 & 20.043 \\
\hline Rialma & 13.500 & 11.697 & 14.239 & 15.512 & 17.320 & 15.312 & 17.961 & 23.815 & 18.057 & 17.077 & 17.072 \\
\hline Rianápolis & 18.828 & 14.781 & 14.319 & 16.624 & 20.927 & 19.383 & 29.202 & 25.107 & 21.888 & 21.252 & 30.215 \\
\hline Santa Isabel & 13.133 & 12.594 & 13.370 & 13.313 & 18.756 & 16.392 & 17.250 & 17.829 & 17.706 & 14.760 & 20.150 \\
\hline $\begin{array}{l}\text { Santa Tereza de } \\
\text { Goiás }\end{array}$ & 9.456 & 9.446 & 9.499 & 9.792 & 10.637 & 11.224 & 11.858 & 12.331 & 14.423 & 14.025 & 14.551 \\
\hline $\begin{array}{l}\text { São Francisco de } \\
\text { Goiás }\end{array}$ & 10.041 & 9.980 & 10.067 & 9.272 & 9.686 & 9.958 & 10.741 & 11.381 & 14.267 & 15.566 & 16.619 \\
\hline São Luiz do Norte & 12.252 & 20.014 & 15.255 & 15.953 & 18.919 & 18.787 & 18.930 & 18.735 & 13.749 & 13.906 & 15.313 \\
\hline Uruaçu & 10.461 & 10.661 & 12.127 & 12.733 & 14.408 & 14.287 & 16.704 & 16.915 & 17.673 & 19.995 & 19.573 \\
\hline
\end{tabular}

Fonte: Elaborado pelos autores com dados disponibilizados pelo IMB (2016).

Tabela 2. Evolução da população estimada de 2003 a 2013 - municípios com pátios de integração multimodal no período de 2003-2013

\begin{tabular}{|c|c|c|c|c|c|c|c|c|c|c|c|}
\hline Município & 2003 & 2004 & 2005 & 2006 & 2007 & 2008 & 2009 & 2010 & 2011 & 2012 & 2013 \\
\hline Anápolis & 298,155 & 307,977 & 313,412 & 318,808 & 325,544 & 331,329 & 335,96 & 334,613 & 338,544 & 342,347 & 357,402 \\
\hline Jaraguá & 34,855 & 35,901 & 36,479 & 37,053 & 38,968 & 41,014 & 41,772 & 41,870 & 42,529 & 43,167 & 45,291 \\
\hline Santa Isabel & 3,501 & 3,441 & 3,407 & 3,374 & 3,485 & 3,580 & 3,575 & 3,686 & 3,693 & 3,701 & 3,814 \\
\hline Porangatu & 39,944 & 40,178 & 40,307 & 40,436 & 39,238 & 40,42 & 40,469 & 42,355 & 42,567 & 42,773 & 44,265 \\
\hline Uruaçu & 33,407 & 33,325 & 33,28 & 33,235 & 33,382 & 34,411 & 34,470 & 36,929 & 37,190 & 37,443 & 38,854 \\
\hline
\end{tabular}

Fonte: Elaborado pelos autores com dados disponibilizados pelo IMB (2016). 
p. 41 - Análise das contribuições econômicas da Ferrovia Norte-Sul nos municípios goianos

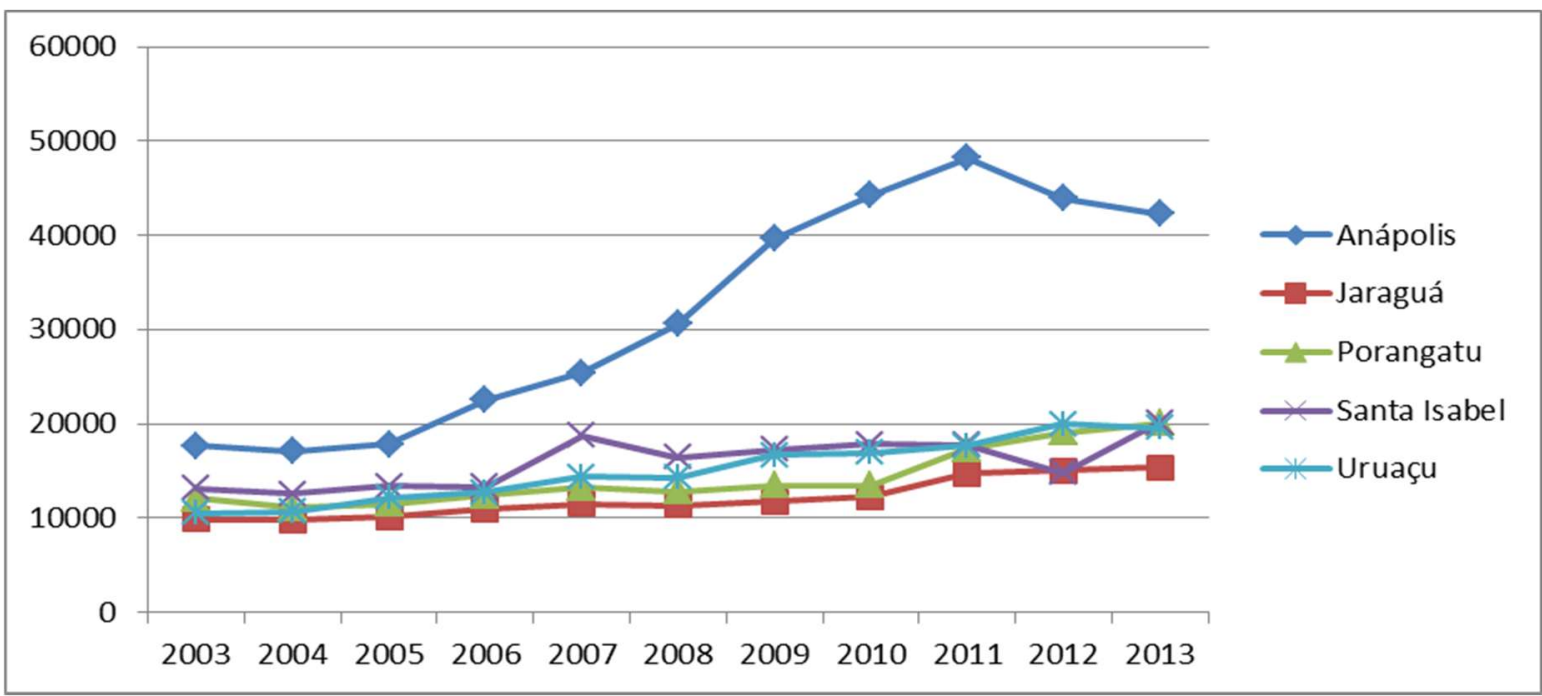

Gráfico 1. Evolução do PIB per capita nos municípios com pátios de integração multimodal no período de 2003-2013

Fonte: Elaborado pelos autores com dados disponibilizados pelo IMB (2016).

Com relação à renda do trabalho, observa-se um comportamento comum em alguns municípios. A renda dos trabalhadores cresce a partir de 2008, período em que as obras da FNS são mais intensamente realizadas, sobretudo nos municípios em que foram construídos os pátios de integração multimodal, e sofre uma ligeira queda a partir de 2013, com a finalização das obras. Tal dinâmica pode ser percebida nos municípios de Campo Limpo de Goiás, Petrolina de Goiás, Porangatu, Rianápolis, Jaraguá e Uruaçu. A Tabela 3 mostra o valor da remuneração média nominal para cada um dos municípios estudados, a partir da renda do trabalho formal. 

[REOESTE]

nepec

Tabela 3. Valor da Remuneração Média Nominal de 2003 a 2015 - municípios selecionados

\begin{tabular}{|c|c|c|c|c|c|c|c|c|c|c|c|c|c|}
\hline Município & 2003 & 2004 & 2005 & 2006 & 2007 & 2008 & 2009 & 2010 & 2011 & 2012 & 2013 & 2014 & 2015 \\
\hline $\begin{array}{l}\text { Alto } \\
\text { Horizonte }\end{array}$ & 171.979 & 249.175 & 1.238 .119 & 2.856 .440 & 4.822 .310 & 6.570 .335 & 8.524 .438 & 7.718 .708 & 7.193 .384 & 9.901 .452 & 9.078 .044 & 10.563.271 & 9.054 .927 \\
\hline Anápolis & 104.177 .283 & 97.839 .011 & 113.381 .377 & 130.665 .676 & 142.767 .632 & 170.049 .814 & 196.733 .511 & 225.815 .565 & 232.027 .888 & 273.193.005 & 280.202 .764 & 297.038 .943 & 294.859 .289 \\
\hline Campinorte & 732.178 & 814.631 & 968.797 & 1.070 .625 & 1.293 .718 & 1.403 .453 & 2.581 .064 & 1.997 .467 & 4.270 .637 & 2.824 .524 & 2.646 .073 & 2.871 .908 & 2.727 .507 \\
\hline $\begin{array}{l}\text { Campo } \\
\text { Limpo de } \\
\text { Goiás }\end{array}$ & 1 & 7 & 15 & 7 & 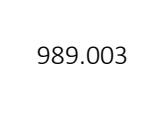 & 1 & 9 & 0 & 1 & 9 & 4 & 0 & 339 \\
\hline Ceres & 4.022 .351 & 4.266 .594 & 5.210 .567 & 5.203 .509 & 5.976 .576 & 6.910 .105 & 7.624 .582 & 8.081 .044 & 9.019 .515 & 9.690 .381 & 11.845 .031 & 13.041 .896 & 13.470 .716 \\
\hline $\begin{array}{l}\text { Estrela do } \\
\text { Norte }\end{array}$ & 343.107 & 300.836 & 383.282 & 418.517 & 492.422 & 549.051 & 638.550 & 677.870 & 3.773 .268 & 1.900 .272 & 892.357 & 824.532 & 826.510 \\
\hline Formoso & 337.095 & 352.115 & 369.128 & 330.823 & 467.980 & 620.187 & 789.045 & 527.784 & 584.771 & 642.655 & 730.989 & 744.554 & 736.167 \\
\hline Jaraguá & 3.946 .788 & 4.535 .371 & 5.886 .652 & 6.870 .009 & 7.356 .260 & 7.653 .645 & 8.596 .794 & 8.686 .429 & 10.312 .061 & 10.989 .824 & 13.203 .230 & 13.473 .327 & 13.058 .607 \\
\hline Jesúpolis & 14.122 & 134.078 & 169.598 & 151.825 & 187.890 & 206.203 & 292.925 & 315.447 & 335.123 & 434.416 & 610.499 & 443.460 & 443.963 \\
\hline Mara Rosa & 902.099 & 1.033 .136 & 1.076 .819 & 1.248 .126 & 1.646 .855 & 2.051 .663 & 2.050 .430 & 1.886 .885 & 2.105 .075 & 2.150 .511 & 2.678 .576 & 2.879 .509 & 2.461 .367 \\
\hline Nerópolis & 6.397 .086 & 7.261 .948 & 7.524 .356 & 8.754 .816 & 9.370 .259 & 9.353 .903 & 11.279 .862 & 12.909 .938 & 14.102 .801 & 15.092 .647 & 17.385 .604 & 16.532 .004 & 15.928 .340 \\
\hline $\begin{array}{l}\text { Ouro Verde } \\
\text { de Goiás }\end{array}$ & 1.363 & 501.768 & 503.540 & 684.508 & 513.448 & 573.257 & 672.408 & 752.708 & 782.781 & 923.351 & 945.878 & 938.274 & 991.900 \\
\hline $\begin{array}{l}\text { Petrolina de } \\
\text { Goiás }\end{array}$ & 874.859 & 863.263 & 828.762 & 948.229 & 1.013 .609 & 1.119 .041 & 1.256 .400 & 6.330 .585 & 2.737 .969 & 1.958 .596 & 2.279 .954 & 1.722 .633 & 1.959 .414 \\
\hline Porangatu & 4.916 .680 & 4.854 .330 & 5.565 .121 & 6.605 .706 & 6.847 .563 & 7.684 .040 & 9.892 .915 & 11.371 .810 & 11.711 .770 & 12.398 .323 & 20.457 .257 & 15.297 .949 & 14.679 .079 \\
\hline Rialma & 1.246 .957 & 1.335 .584 & 1.668 .369 & 1.701 .657 & 2.007 .654 & 2.070 .018 & 2.339 .956 & 2.655 .322 & 2.814 .709 & 3.268 .835 & 3.639 .773 & 3.824 .627 & 3.088 .647 \\
\hline Rianápolis & 770.582 & 687.074 & 732.305 & 862.433 & 864.568 & 1.419 .602 & 3.052 .588 & 3.520 .003 & 2.551 .415 & 1.797 .638 & 2.319 .885 & 2.068 .504 & 1.962 .303 \\
\hline Santa Isabel & 245.806 & 272.313 & 352.394 & 318.792 & 360.009 & 420.797 & 558.927 & 578.519 & 675.034 & 680.375 & 740.425 & 689.660 & 706.417 \\
\hline $\begin{array}{l}\text { Santa } \\
\text { Tereza de } \\
\text { Goiás }\end{array}$ & 44.969 & 430.626 & 421.882 & 660.714 & 473.740 & 505.175 & 1.047 .577 & 609.143 & 633.729 & 713.560 & 840.855 & 751.434 & 731.918 \\
\hline $\begin{array}{l}\text { São } \\
\text { Francisco } \\
\text { de Goiás }\end{array}$ & 4.894 & 629.987 & 540.454 & 783.880 & 79.052 & 693.700 & 970.623 & 1.204 .570 & 1.265 .657 & 1.421 .528 & 1.518 .914 & 1.734 .484 & 2.531 .416 \\
\hline $\begin{array}{l}\text { São Luiz do } \\
\text { Norte }\end{array}$ & 1.339 & 1.213 & 335.505 & 322.943 & 2.862 & 53.041 & 900.656 & 589.003 & 1.130 .288 & 1.348 .252 & 1.669 .250 & 1.768 .818 & 1.752 .623 \\
\hline Uruaçu & 3.274 .215 & 3.880 .373 & 5.013 .368 & 5.590 .621 & 7.474 .130 & 10.310 .772 & 11.128 .269 & 17.942 .273 & 17.064 .457 & 13.032 .609 & 13.861 .534 & 17.697 .398 & 14.780.777 \\
\hline
\end{tabular}

Fonte: Elaborado pelos autores com dados disponibilizados pela RAIS (2016). 

O Gráfico 2 mostra a evolução da remuneração média nominal (renda do trabalho) para os municípios de Jaraguá, Porangatu e Uruaçu. A dinâmica discutida no parágrafo anterior pode ser exemplificada por esses municípios. A remuneração do trabalho começa a crescer de forma significativa a partir do ano de 2008 nos três municípios, e nos últimos períodos analisados a renda cai (Uruaçu e Porangatu) ou permanece praticamente constante como se observa em Jaraguá.

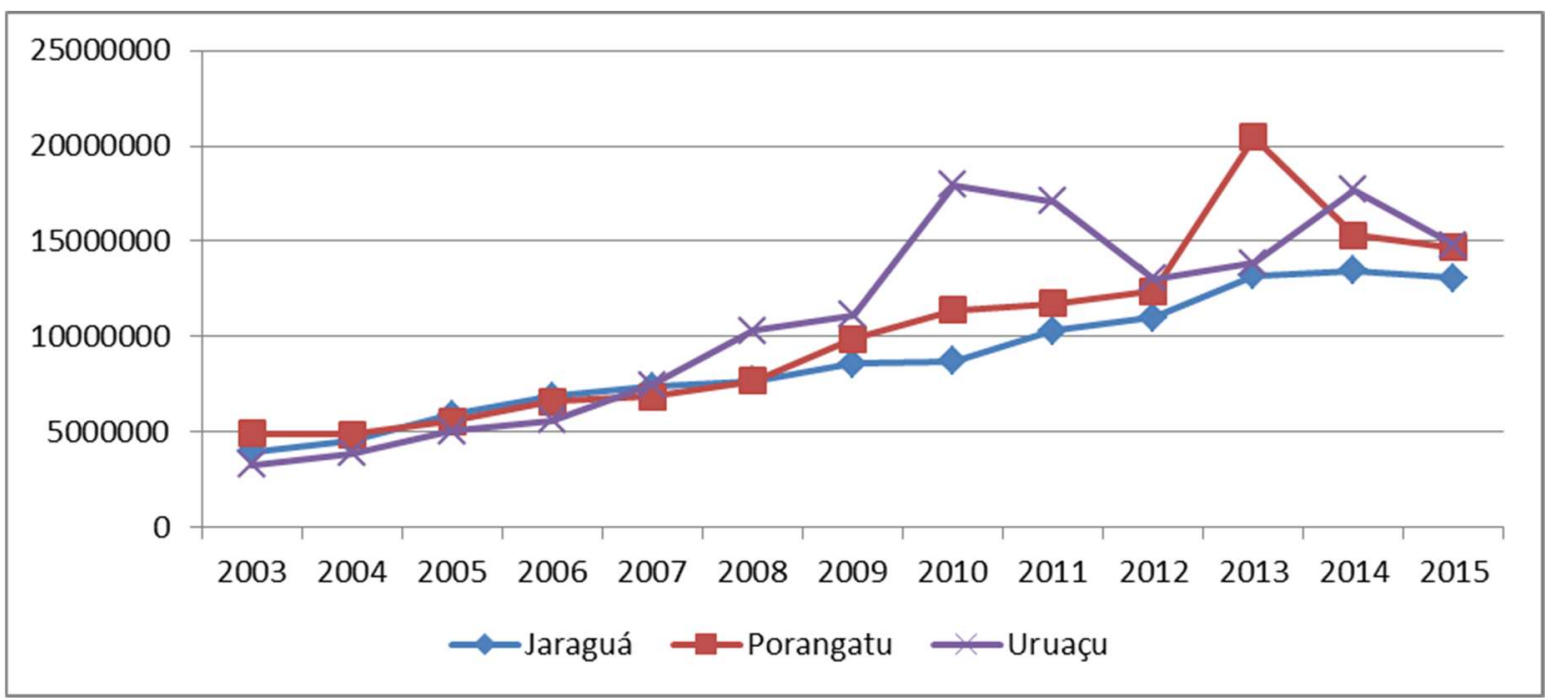

Gráfico 2. Evolução da Remuneração Média Nominal em Jaraguá, Porangatu e Uruaçu no período de 2003 a 2015

Fonte: Elaborado pelos autores com dados disponibilizados pela RAIS (2016).

Tal desempenho pode ser explicado pelo aumento do emprego formal nesse período, pois grandes obras de infraestrutura demandam considerável quantidade de mão de obra, o que reflete na renda média dos trabalhadores. Além disso, os municípios da área analisada, sobretudo da Região Norte do estado, apresentam em sua maioria renda do trabalho menor que a média do estado, então, a melhoria deste indicador nesses municípios é de suma importância, pois mostra que a ferrovia pode ser capaz de impactar positivamente esses e outros indicadores em uma região que necessita de estímulos ao desenvolvimento, assim como prosperar a renda e o emprego da população.

No que tange à arrecadação tributária municipal, medida pelo ISSQN², a maior parte dos municípios analisados na pesquisa apresentaram um significativo aumento na arrecadação a partir dos anos de 2008 e 2009, com ápice no ano de 2010, sofrendo drástica redução já em 2011. Esta dinâmica é observada, principalmente, nos municípios com pátios de integração intermodal: Jaraguá, Porangatu, Uruaçu e Santa Isabel.

\footnotetext{
${ }^{2}$ Imposto municipal mais significativo em termos de volume arrecadado.
} 

[REOESTE]

$11 \mathrm{ejec}$

Tabela 4. Valor da Arrecadação Tributária (ISSQN) de 2003 a 2015 - municípios selecionados

\begin{tabular}{|c|c|c|c|c|c|c|c|c|c|c|c|c|c|}
\hline Município & 2003 & 2004 & 2005 & 2006 & 2007 & 2008 & 2009 & 2010 & 2011 & 2012 & 2013 & 2014 & 2015 \\
\hline $\begin{array}{l}\text { Alto } \\
\text { Horizonte }\end{array}$ & 6.994 & 68.008 & 1.366 .891 & 4.186 .063 & 2.164 .841 & 2.673 .201 & 4.304.943 & 5.284 .385 & 4.940 .040 & 6.577 .488 & 7.743.771 & 9.823 .507 & - \\
\hline Anápolis & 9.261 .149 & 10.438 .333 & 15.972 .497 & 22.779 .208 & 26.096 .231 & 28.171 .343 & 30.573 .222 & 38.083 .198 & 48.285 .231 & 48.400 .258 & 56.432 .786 & 60.829 .136 & 56.739 .858 \\
\hline Campinorte & 125.699 & 122.590 & 224.001 & 235.469 & 304.689 & 16.608 .985 & 531.278 & 3.896 .029 & 1.799 .926 & 1.269 .468 & - & 1.262 .212 & - \\
\hline Campo & & & & & & & & & & & & & \\
\hline $\begin{array}{l}\text { Limpo de } \\
\text { Goiás }\end{array}$ & 53.162 & 57.756 & 114.817 & 54.781 & 27.919 & 501.666 & 189.699 & 374.398 & 182.061 & 168.928 & 284.097 & 249.418 & - \\
\hline Ceres & 117.276 & 142.917 & 384.046 & 1.149 .591 & - & 1.333 .442 & 1.383 .918 & 1.452 .872 & 2.042 .572 & 2.495 .883 & 2.352 .386 & 4.577 .911 & 4.276 .597 \\
\hline $\begin{array}{l}\text { Estrela do } \\
\text { Norte }\end{array}$ & 11.445 & 8.025 & 2.183 & 51.350 & - & 20.955 & 134.294 & 1.230 .032 & 187.149 & - & - & 487.050 & 564.637 \\
\hline Formoso & 5.374 & 3.302 & 42.347 & 49.513 & 39.179 & 48.385 & 70.111 & 80.874 & 107.979 & 198.875 & 134.318 & 72.086 & - \\
\hline Jaraguá & 215.160 & 350.433 & 748.640 & 1.149 .604 & 1.412 .096 & 3.318 .229 & 5.760 .277 & 5.889 .789 & 4.017.407 & 3.347 .375 & 2.014.930 & 4.201 .561 & 2.864 .376 \\
\hline Jesúpolis & 4.735 & 4.431 & 28.608 & 37.311 & 49.526 & 122.520 & 98.980 & 794.739 & 374.799 & 212.283 & 225.400 & 237.579 & 148.290 \\
\hline Mara Rosa & 447.502 & - & 316.271 & 21.013 & 8.749 & 76.069 & 1.958 .351 & 5.266 .154 & 1.022 .903 & 508.239 & - & 1.195 .739 & - \\
\hline Nerópolis & 3.220 .066 & 2.724 .818 & 3.271 .733 & 3.729 .885 & 3.424 .224 & 3.754 .033 & 3.506 .147 & 3.934 .185 & 5.439 .836 & 4.416 .448 & 6.585 .999 & 6.219 .747 & 6.113 .254 \\
\hline $\begin{array}{l}\text { Ouro Verde } \\
\text { de Goiás }\end{array}$ & 116.775 & 69.379 & 352.361 & - & 7.245 & 500.916 & 93.931 & 985.414 & 221.694 & 77.006 & 320.975 & 479.692 & 524.675 \\
\hline $\begin{array}{l}\text { Petrolina de } \\
\text { Goiás }\end{array}$ & 118.216 & 221.694 & 352.035 & 251.623 & 247.735 & 444.546 & 557.943 & - & 3.998 .419 & 605.327 & 1.107 .568 & 2.707.378 & 1.153 .733 \\
\hline Porangatu & 864.342 & 1.104 .922 & 1.283 .739 & 1.717.099 & 1.990 .247 & 1.987 .520 & 8.235 .425 & 13.001 .398 & 7.044 & 3.240 .624 & - & 4.804 .668 & 4.207 .051 \\
\hline Rialma & 51.647 & 41.468 & 88.266 & 151.904 & 190.430 & 212.032 & 250.958 & 260.030 & 226.498 & 341.913 & 368.806 & 1.447 .714 & 424.439 \\
\hline Rianápolis & 12.747 & 4.405 & 15.688 & 56.287 & 74.375 & 316.897 & 179.628 & 1.080 .426 & 354.590 & 116.929 & 268.949 & - & - \\
\hline Santa Isabel & 10.005 & 12.548 & 22.486 & 22.802 & 20.312 & 195.366 & 804.316 & 7.986 .964 & 3.221 .200 & 252.786 & 743.596 & - & 897.233 \\
\hline $\begin{array}{l}\text { Santa Tereza } \\
\text { de Goiás }\end{array}$ & 14.855 & 26.471 & 149.779 & 117.757 & 91.620 & 66.868 & 98.000 & 501.069 & 983.890 & 510.730 & 96.582 & 66.949 & 88.715 \\
\hline São & & & & & & & & & & & & & \\
\hline $\begin{array}{l}\text { Francisco de } \\
\text { Goiás }\end{array}$ & 27.876 & 101.528 & 30.349 & 41.990 & 90.496 & 226.113 & 189.145 & 1.472 .177 & 583.513 & 929.820 & 307.604 & 2.043 .949 & 1.250 .063 \\
\hline $\begin{array}{l}\text { São Luiz do } \\
\text { Norte }\end{array}$ & 32.342 & 18.431 & 41.044 & 121.763 & 214.958 & 276.720 & 310.454 & 3.189 .474 & 1.039 .411 & 103.861 & - & 143.952 & 329.317 \\
\hline Uruaçu & 572.500 & 658.130 & 790.170 & 992.381 & 1.039 .571 & 1.105 .407 & 3.206 .598 & 15.729 .684 & 3.757 .675 & 3.460 .406 & 3.712 .391 & 3.761 .605 & 3.030 .835 \\
\hline
\end{tabular}

Fonte: Elaborado pelos autores com dados disponibilizados pelo SICONFI (2016). 



\section{nejpec}

Mas, em outras localidades onde passam os trilhos da FNS, como: Campinorte, Mara Rosa, Estrela do Norte, Jesúpolis, Jaraguá, Ouro Verde de Goiás, Rianápolis, São Luiz do Norte e Santa Tereza de Goiás, pode-se verificar a mesma tendência.

O Gráfico 3 ilustra esse comportamento nos municípios de Jaraguá, Porangatu, Santa Isabel e Uruaçu, onde foram construídos pátios de integração multimodal. A arrecadação tributária atinge valores até cinco vezes maiores do que aqueles verificados nos períodos anteriores à construção da FNS. Depois dos anos de auge de construção da ferrovia os valores voltam para o patamar anterior na maioria dos municípios.

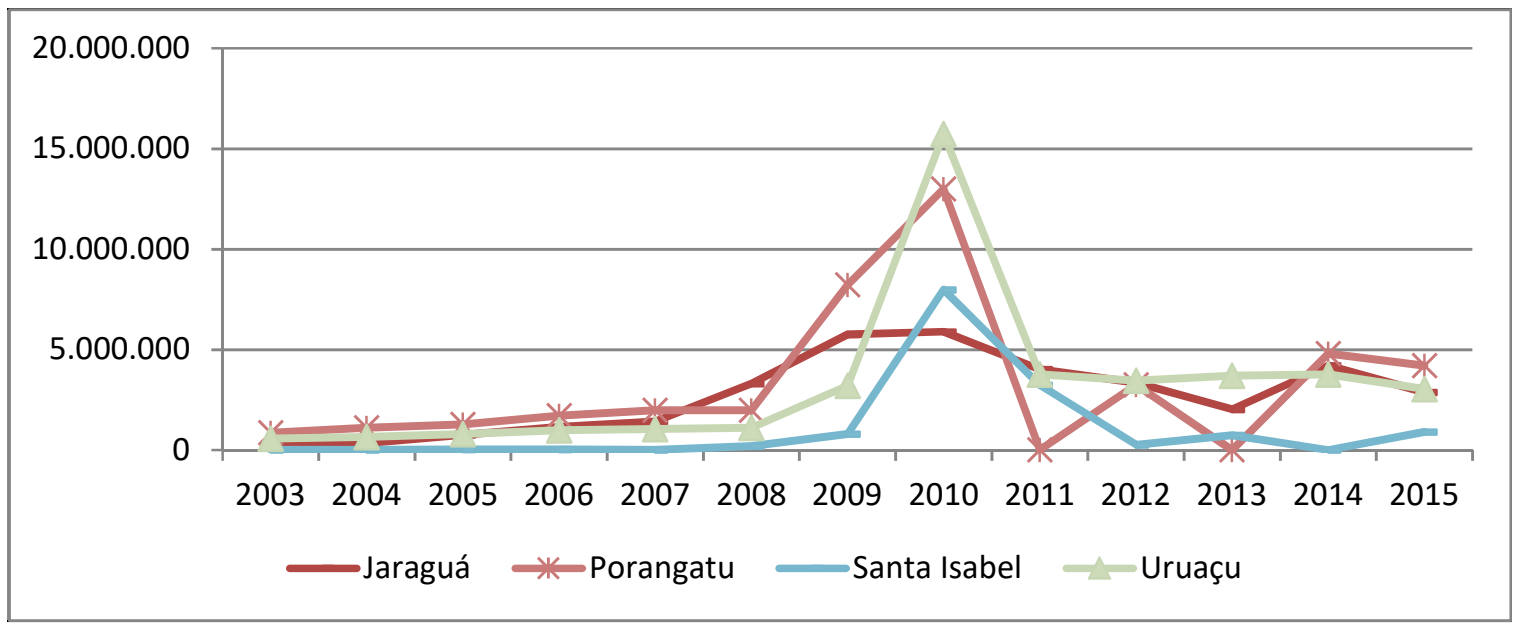

Gráfico 3. Evolução do ISSQN nos municípios com pátios de integração multimodal: 2003 a 2015

Fonte: Elaborado pelos autores com dados disponibilizados pelo SICONFI (2016).

O mesmo comportamento pode ser observado nas localidades que não são comtempladas com a construção de pátios da FNS. Mesmo naqueles municípios com arrecadação relativamente mais baixa, houve uma melhora no indicador de 2009 a 2011, como mostra o Gráfico 4.

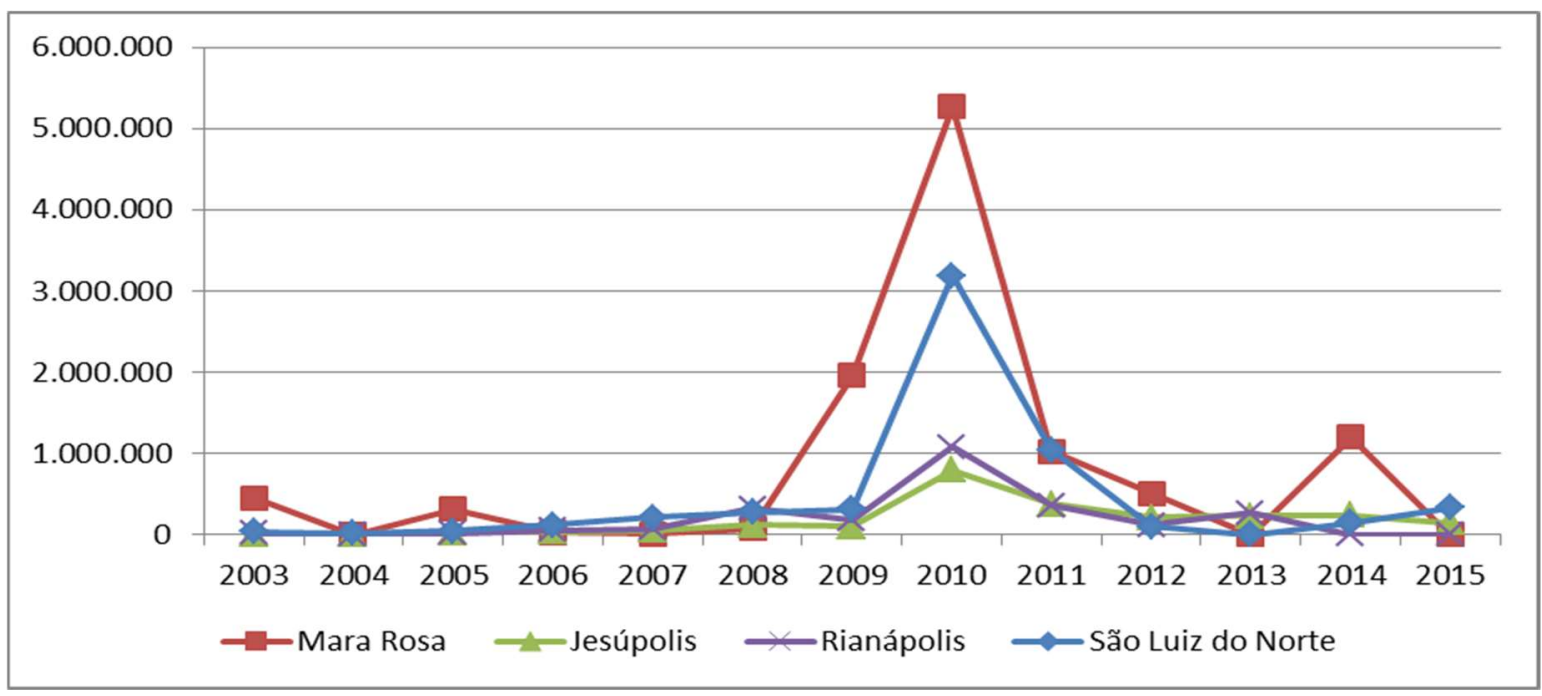

Gráfico 4. Evolução do ISSQN nos municípios cortados pela FNS: 2003 a 2015 Fonte: Elaborado pelos autores com dados disponibilizados pelo SICONFI (2016). 
A dinâmica observada ao analisar a evolução do ISSQN nos municípios cortados pela FNS em Goiás pode ser explicada pelo fato dos campos de construção da ferrovia demandar uma quantidade maior de serviços e mão de obra local, ou seja, dos próprios municípios, o que fez com que a arrecadação aumentasse nos períodos de ênfase da construção. E a queda significativa verificada nos anos seguintes reflete o término das obras, contando que se cessaram a demanda por serviços nas localidades. Além disso, os investimentos que poderiam chegar aos municípios estão sendo inibidos pelo fato da ferrovia não estar efetivamente em operação, impactando de forma negativa a evolução da arrecadação e das demais variáveis econômicas nos municípios estudados.

\section{CONSIDERAÇÕES FINAIS}

O objetivo principal da pesquisa consistiu em analisar as contribuições econômicas da FNS nos municípios goianos que contemplam a passagem dos trilhos no trecho Palmas/TO - Anápolis/GO. Para atingir o objetivo proposto foram escolhidas para análise três variáveis econômicas: PIB per capita, renda do trabalho e arrecadação tributária.

Os resultados mostraram que o produto ainda não foi impactado pela realização das obras da FNS nos municípios analisados. Isso quer dizer que apenas a construção da ferrovia não foi suficiente para gerar um incremento no crescimento econômico de maneira endógena. Em relação à remuneração ou renda do trabalho, observou-se que o período de construção da FNS foi importante para o aumento desta variável, gerando mais empregos e aumento a renda. No entanto, esse fenômeno não se manteve após o término das obras da FNS, como é o caso de Jaraguá, Uruaçu e Porangatu. Esse comportamento apesar de não se verificar em todos os municípios é um resultado esperado, pois grande parte deles apresenta renda do trabalho menor que a média estadual, sendo assim, empreendimentos que demandam mão de obra local é um importante estímulo ao desenvolvimento. No entanto, seriam necessárias outras políticas de estímulo para que este indicador continuasse a crescer, como a própria operação da FNS promovendo a atratividade de investimentos.

A evolução da arrecadação tributária aponta para um resultado semelhante àquele encontrado pela análise da renda do trabalho. Há um incremento da variável nos períodos de construção da FNS, mas que não perduram após o término das obras. Essa é uma característica verificada em mais da metade dos municípios analisados. Isso significa que as obras de infraestrutura trouxeram benefícios, mas para que esses benefícios se mantenham seriam necessários outros incentivos à atividade econômica.

Destaca-se que todos os indicadores analisados apontaram que após o término das obras da FNS verificou-se pouco incremento em relação aos seus níveis anteriores. Tal fato revela que os municípios estudados não conseguiram alterar suas dinâmicas econômicas mesmo apresentando um período propulsor. Assim, é evidente a necessidade de operação da ferrovia para que novas demandas sejam incrementadas, principalmente, por conta da posição favorável que o estado de Goiás ocupa no território brasileiro, favorecendo a redução de custos logísticos a partir desse modal. 
p. 47 - Análise das contribuições econômicas da Ferrovia Norte-Sul nos municípios goianos

\section{REFERÊNCIAS}

ADORNO, L. F. M. Ferrovia Norte-Sul: Na Trilha da Questão Regional. Palmas: Unitins, 1999.

ARAÚJO, M. P. Infraestrutura de Transporte e Desenvolvimento Regional: uma abordagem de equilíbrio geral inter-regional. 2006. 115f. Tese (Doutorado em Ciências). Escola Superior de Agricultura "Luiz de Queiroz". Universidade de São Paulo. Piracicaba, $2006 . \quad$ Disponível em: <http://www.teses.usp.br/teses/disponiveis/11/11132/tde-07062006162615/pt-br.php.> Acesso em: 08 set. 2016.

BARAT, J. Logística, Transporte e Desenvolvimento Econômico: A visão macroeconômica. São Paulo: Editora CLA, vol. III, 2007.

BATISTA - FILHO, José Anunciação. A Infraestrutura de Transporte e Impactos dos Investimentos da Construção da Ferrovia Norte-Sul no Tocantins: Uma Abordagem Insumo - Produto. 2009. 200f. Dissertação (Mestrado em Desenvolvimento Regional e Agronegócio) - Universidade Federal do Tocantins, Palmas, 2009.

CAIXETA-FILHO, J. V.; MATINS, R. S. Gestão Logística do Transporte de Cargas. 1.ed. São Paulo: Editora Atlas, 2011.

CAMPOS, F. R. A Influência da Ferrovia Norte-Sul no Desenvolvimento Regional do Território Goiano. 2015. 258f. Tese (Doutorado em Geografia). Universidade Federal de Goiás. Goiânia, 2015.

CAMPOS, F. R.; CASTRO, A. C. Contribuições da Construção da Ferrovia Norte-Sul nos Munícipios do Centro-Norte Goiano. Conjuntura Econômica Goiana, no 28, mar. 2014.

CORREIA, A. M.; OLIVEIRA, E.A.A.Q. Importância da Ferrovia Norte-Sul Para O Processo de Industrialização Local do Município de Gurupi-To. XIV Encontro Latino Americano de Iniciação Científica e X Encontro Latino Americano de PósGraduação. Universidade do Vale do Paraíba, 2010. Disponível em: http://www.inicepg.univap.br/cd/INIC_2010/anais/arquivos/RE_0488_0252_01. pdf. Acesso em: 22 jul. 2018.

DIÁRIO DA MANHÃ. Centro-Oeste: O caminho do novo Brasil. Suplemento Especial Ferrovia Norte-Sul. Goiânia, ago. 1988.

IMB, Instituto Mauro Borges de Estatística e Estudos Geoeconômicos. Estatísticas Municipais (Séries Históricas). Disponível em: < http://www.imb.go.gov.br/perfilweb/estatistica_bde.asp>. Acesso em: 06 set. 2016.

RAIS, Relação Anual de Informações. Disponível em: < http://bi.mte.gov.br/bgcaged/login.php>. Acesso em: 06 set. 2016.

REIS, E. A.; REIS, I. A. Análise Descritiva de Dados Síntese Numérica. Instituto de Ciências Exatas. Departamento de Estatística. Universidade Federal de Minas Gerais: 1a 
ed. 2002. Disponível em: <ftp://ftp.est.ufmg.br/pub/rts/rte0202.pdf>. Acesso em: 06 out. 2016.

SEGPLAN. Ferrovia Norte-Sul. O caminho da integração. Revista Economia e Desenvolvimento. Conjuntura Socioeconômica de Goiás, Goiânia: SEGPLAN, ano 10, n. 28, out. 2008.

SICONFI, Sistema de Informações Contábeis e Fiscais do Setor Público Brasileiro. Disponível em: https://siconfi.tesouro.gov.br/siconfi/pages/public/consulta_finbra/finbra_list.jsf ;jsessionid=95HE8M7PcRW2UCk571xSTPfP.node3>. Acesso em: 05 set. 2016.

VALEC. Ações e Programas - Ferrovias VALEC. Disponível em: http://www.VALEC.gov.br/acoes_programas/FNSFerroviaNorteSul.php. Acesso em: 03 jan. 2017.

VALEC. Relatório de impacto ambiental. Divisa Petrolina de Goiás/ Jesúpolis - Ribeirão Sete Voltas (Goianésia). Ministério dos Transportes. Engenharia, Construções e Ferrovia S/A. 2002.

VALEC, Trecho Açailândia (TO) - Uruaçu (GO) - Anápolis (GO). Disponível em: < http://www.VALEC.gov.br/acoes_programas/FNSPalmasUruacuAnapolis.php>. Acesso em: 06 set. 2016. 